\title{
The Role of Information Technology (IT) in Development and Increase of the Efficiency of Human Resources
}

\author{
Reza Alami (Corresponding author) \\ Department of Management Lincoln University College, Malaysia, Branch Iran \\ Omolbanin Hashemi Gorji \\ Department of Education and Training, Galikash City, Golestan Province, Iran
}

\begin{abstract}
Mehdi Shokri Asrami
Department of Ph.d in Information Technology in Lincoln University College, Malaysia, Branch Iran
\end{abstract}

Hanieh Rasouli Saravi

Department of Management Lincoln University College, Malaysia, Branch Iran

Marziezh Jafari Soteh

Senior Researcher in Department of Education and Training, Province Mazandaran, Iran

Fatemeh Rajabi Ahangari

Department of Education and Training, Ghaemshahr, Province Mazandaran, Iran

Received: November 22, 2015 Accepted: April 30, 2016 Published: May 4, 2016

doi: 10.5296/jsss.v3i2.8602 URL: http://dx.doi.org/10.5296/jsss.v3i2.8602 


\begin{abstract}
Information Technology (IT) as a set of produced ideas is available for individuals and organizations through hardware mechanisms and plays a major role in the development of human resources. In today's world, IT is the key factor of human development in organizations and communities. Trends and results of the literature review confirm contribution of the IT tools in human resources area i.e. to accomplish assigned human resources tasks by using the source of IT capabilities. In the current era the use of information systems and new technologies, especially IT in organizations and communities is the most important tool to improve efficiency and it will accelerate movement toward this direction. Improper use of it can impose problems to the organization and it also reduces productivity. The aim of this paper is to investigates the impact of IT on the productivity of human recourses and gives a brief overview about possibilities of IT usage in human resources field for measuring and tracking human capital and using the human resources information system generally. The results of this, study revealed that there is significant relationship between use of IT and human resource management functions, also a positive and significant effect of the ICTs on employment rate.
\end{abstract}

Keywords: Human resources development, Information technology, Internet, Organizational learning

\title{
1. Introduction
}

Today all organizations claim that human resources are their biggest capital and it is known as the only influencing factor on the development. The process of development and growth, without human involvement is ineffective; because human is the goal and also means of achieving development (Kolinsky, 1998). In an era when by a small negligence competitors surpass and customers pose complex and diverse demands, human resource development has become one of the major competitive advantages of the period (Baldwin \& Ford, 1988). The axis of human resources development is the existence of new and practical information, information in a logical process called information technology can help to create and develop new capabilities in human resources. One of the main affecting factors in today's organizations and employees is changes in technology. In recent years, information technology has shown a sustainable growth (Hajizade Moghadam, \& Vajdi Dastgerdi, 2010). In fact, one of the bright areas of human resource management department is taking advantage of IT. Researchers believe that the application of information technology in organizations promises fundamental change in all fields. Information technology helps organizations to save their human resources information safer, more accessible and more thoroughly and provide managers with the ability to analyze and make better decisions about their organization's human resources. With the advent of information technology into an organization, human resource management practices are changed (Ahmadi, 2011). This change can be effective if the activities that Information technology can do are known and the context for performing them is provided. Subsequently, human resource management has become familiar with the new situation in order to by taking advantage of Capacity created by Information technology; improve the performance of organization's human resources 
(Mahmodi, 1993). Although this study has a broad topic which is of high importance, but without a doubt, the Internet and information and communication technology, can be one of the most important factors affecting the labor market and personnel management. The purpose of this study was to evaluate some changes made by information and communication technology and Internet in in the development and increasing productivity of human resources and as a result new ways of working, such as being a virtual employee is possible.

\section{Human Recourse Development}

Human resource development is continuous growth and all-round development and improvement of people. In other words, the topic of development of human resource covers all aspects such as the development of an individual's working life, social life, private life and cultural and spiritual issues. Human resource development means producing thoughts and ideas by staff and its new concept requires employees be equipped with quality and skills and with compassion and commitment, they offer their abilities, energy, expertise and thought in order to fulfill the mission of the organization (Hajizade Moghadam, \& Vajdi Dastgerdi, 2010). Almost all management and economics scholars have accepted that high-quality human resources are a key element of economic development at the macro and micro level (Roshan, 2003). Therefore, organizations, as they have development plans for financial resources and physical capital, should include plans in their strategic programs for the development of human resources with a different and better view than other sources available to organizations. The issue of human resource development as a key, fundamental and important issue is one of the most essential measures presented in organization and human resources management (Davoudi, 1999).

\section{The Concept of Human Resources Productivity}

Productivity is to maximize the use of resources, manpower and scientific measures to reduce costs and to satisfy employees, managers and consumers. Another definition of human resource productivity is Maximum use of human resources in order to move in the direction of the organization's goals with minimal time and cost involved. Another definition of productivity provided from the systemic perspective: it specifies the relationship between the data (Inputs) and outputs. Accordingly, productivity reflects the efficiency of combination of factors in the production process. That is, productivity increases if the facilities are used properly. So if the human resources as one of the factors of production are well used, human resources productivity will also increase. Generally, productivity has two components. The first component is efficiency and effectiveness of the activity is another component. Efficiency refers to the ability to obtain outputs from less input. In other words, efficacy is working well. The effectiveness refers to matching of the results of the work with the desired goals and in other word doing good job can be called effectiveness. So in a general definition productivity is "just doing the right thing" (Abile, Movafaghi, 2003). So if things or organizational tasks are well specified and requirements for each responsibility and how to do it is determined and on the other hand, if people are assigned to their tasks and jobs properly and according to their talent, ability and knowledge, it is expected that human resources productivity increases. 


\section{The Role of Information Technology in Increasing the Efficiency of Human Resources}

Information Technology (IT) as a set of produced thoughts and ideas is available to individuals and organizations through hardware mechanisms and plays a major role in the development of human resources. In today's world, information technology is the basis for human development in organization and society and also determines the main axis of human resources development and its nature in accordance with Society and people's needs. In human resource development, new human capacities must be always recognized in order to the development of human capabilities and quality be carried out as a permanent process (Gabcanova, 2013). Realization of this is dependent on the use of IT because in IT process information is constantly produced, processed, distributed and managed. Thus, IT will solve the problems when it serves the development of human beings and human capabilities are integrated together and lead to the development and productivity (Wars, 1998). On this basis, and given the role of IT in the development of human resources this article tries to explain the concept of information technology and human resource development and deal with the role of IT in various aspects of development and productivity of human resource.

\subsection{The Concept of Information Technology}

Information technology is a set of techniques and equipment which are created with the aim of optimizing information systems. The disadvantages of IT are often caused by improper use of this system. Inaccurate and incomplete design of information systems 'designers and IT engineers or improper use of the users of these systems, often creates problems and disorders. The definition of Information technology because of its flexible nature must be accompanied with a dynamic approach. Information technology is more a type of strategy, idea, thought and a tool with innovation in human areas (Ahmadi, 2011). In the present age implementation, development and maintenance of information systems is as one of the most important business processes in IT management and managers and organizations are faced with new challenges in this field. Information technology before being a hardware system and a set of patterns is an intellectual and cultural system and it can be called the culture of information production. Without creating a culture of information production, IT systems cannot be sustained. Therefore, what is important in IT is information-oriented thinking. Information technology forms from connection and combination of a series of useful produced thoughts and computers, supercomputers, wires and cables are not such tools. In information technology, the thought of wise people produces information. Information technology means the methods of production and collection of information and using it in society and organization. IT made it possible to have access to information from anywhere and by anybody by making computer programs smaller, cheaper and easier (Mohammad Nejad, 1394).

\subsection{The Nature of Information Technology}

If the Industrial Revolution in the early nineteenth century replaced machines with people and increased the quantity, quality, speed and accuracy of production and facilitated and expedited communication compared to the herders and farmers 'era, In the late twentieth century and beginning of the third millennium, Electronic revolution led to the disappearance 
of boundaries between the countries and organizations and it facilitated communication and data transfer (Fasanghari, Roudsari, \& Chaharsooghi, 2008). In the age of information and electronic communications all elements of the world riding on the third wave of Alvin Toffler in economic, society and global markets are challenged to gain a greater share of the global benefits. In this age everything has a new nature. People from all over the world exchange and trade in the blink of an eye, citizens make contact with their country's system of government in electronic format and in minimum time and express their needs or respond to their demands, organizations and institutions are related to citizens and exchange information (Davoudi, 1999). In short, since in the present era and by electronic revolution all elements and systems can be connected in a minimum of time and exchange information, Internet and computer have changed people's life and ways of communicating with others. Basically, new technologies have changed all aspects of human society more or less. In recent years, the importance of Internet and information technology - both in the commercial space and the private space -have significantly increased (particularly with the increase in Internet users and Internet services). The greatest impact of the Internet and information technology has been on educated, skilled people and ones interested in success, especially those people from this collection who deal with information and communication technology on a regular basis. Since, educated, skilled people and ones interested in success are working in important situations in the organizational hierarchy; therefore, they have a greater effect on the overall success of the organization, we also need to pay attention on the impact of internet on this group of employees.

\subsection{The Use of the Internet in New Ways of Working}

Through the development of the Internet and more widely the development of information and communications technology (ICT) with full fluctuations it has had in the past two decades-new and more different facilities have been provided for working and structuring of organizations (Walwyn, 2003). This development will continue in the future and its scope involves all employees. Undoubtedly, the employees and their work environment, in terms of jobs, working conditions and many other things have been influenced by the Internet and information technology. Because - in today`s business environment- People and their knowledge are considered as the most vital asset of the organization, it is obvious that every company needs to be informed and ready to accept new changes. Knowledge and understanding of the new orientation, not just for IT professionals is necessary, but managers must be aware of them (Nejdairani, Rasouli, \& Behravesh, 2011). Managers who are seeking to develop their human resources, should pay great attention to this subject and make the maximum use of it.

\subsubsection{Remote Working}

There are several definitions of remote working or "virtual work". This term is used interchangeably with different terms. For example, virtual communication, location flexibility, electronic cottage can be mentioned. As discussed in the annual report of the Commission of Europe in 2000, virtual working has a broad concept that their common element is the use of computer and virtual communication for a geographical change in performing a job which 
has been accepted (MirFakhraee, 2001). Virtual working means that with the help of information technology, it is tried to guide the work to the employees instead of guiding employees towards the job. Virtual working has a lot of advantages that can be summarized and classified from three perspectives: individual, institutional and macro-social. From organizational perspective, Virtual communication brings benefits such as high productivity.

\subsubsection{Using Internet to Develop Employees' Capabilities and Development of Human Resources}

Completion of existing knowledge and acquiring new knowledge is one of the strong motivational factors for an individual who has covered his basic and primary needs. Therefore, as acquiring new knowledge is considered a key factor for an individual's success, it is also important for an organization's success. Internet-based technology offers many opportunities for finding new knowledge and skills. First, at the corporate level, Internet provides the context for faster access to technological and scientific innovations compared to other companies and research institutions (Gabcanova, 2013). At the individual level, internet introduces itself as a vast, and searchable database containing a collection of web pages, newsgroups, mailing lists and network information streams.

\subsection{The Effect of Information and Communication Technology on Employees}

Information and communication technology and Internet has affected not only IT professionals and employees who regularly use information technology in their work environment, but also it has affected organization's environment, organization itself and in general the social world (Drucker Peter, 1993). Managers should be aware of these changes and try to understand and adapt them. Especially at the level of employee motivation, we can expect major changes. Moreover, social evaluators predict fundamental and profound changes in the society's level. In this situation, maintaining the motivation of employees is the first and most important duty of the managers. The results of IT professionals research showed that the most important advantage that IT professionals expect from a company is the possibility of working at home. To the extent that they give importance to the salary and the opportunities of progress (Baldwin, 1988). Masterosefsno and piñata (2005), conducted study the dynamics of innovation and employment during the periods 1994-1996 and 1998- 2000 for ten European countries and eleven industries. The results of this study show that ICT has a positive effect and negative effect on wages on total demand, production and therefore employment.

According to Benavente and Lauterbach (2008) the productive innovation has a significant positive effect on employment at the various levels of skills. Information and Communication Technology offers enormous opportunities for improving information management in organizations. By taking advantage of these opportunities, it is possible to make better use of employees' knowledge. One of these opportunities is using company's internal networking system which is based on the services and agreements in accordance with the internet. The inter-organizational network provides the possibility of storing, organizing, processing, maintaining and sharing of information among members of the organization. At the same time, the release of such information (information on the intranet) to outside the organization 
can be prevented. Especially the use of ICT has higher growth in productivity and utility of services firms. These effects are more when non-technological innovation combined with technological innovation. According to Koellinger (2006), "ICT impact on employment in each country can be studied and analyzed in two different ways, which include: 1 . Using ICT causes that works be done by less labor and thereby employment be reduced. 2 . The use of ICT will lead to new innovations that increase the growth and employment".

\subsection{The Place of Organizational Learning in Human Resources Development and the Role of Information Technology in It}

Organizational learning is effective in the development of individuals within an organization (managers and employees) and the experience of the organizations that have taken the action confirms this claim. An important point to emphasize here is that Information technology and particularly the Internet is very effective in facilitating organizational learning by facilitating and improving communication among employees, the effectiveness of the learning process, the availability of information anytime and anywhere is needed, on-line information of managers about skills and abilities of individuals within the organization and timely recognition of their weaknesses and many other aspects (Ghorbani \& Sangani, 2011). Organizations that wish to develop skills and abilities of its employees as soon as possible and to catch up with the competitive market and rapidly changing industry need to design smart systems that through internet and with high efficacy are able to deal with the learning of employees in the desired field and implement their objectives in this regard (Soltani, 1999).

\section{Enhancing Opportunities with the Help of Information Technology in Developing Human Resources}

The role of IT in human resource development is the existence of practical and new information and information in a logical process called IT can help to develop new capabilities in human resources. In general IT helps to develop human resources in the following aspects:

\subsection{Professional Development}

One of the operational signs of developed human which helps employment or facilitates it, is having skills that have potentials for growth and development. When technical capacities are ready to develop but its proper content is not provided, skills become obsolete after a while and do not meet the needs of the organization and the individuals (Giviyan, 2001). At this time, information refreshes empty and obsolete capacities and helps to develop staff"s skill development. This is due to the fact that new information creates new expectations in the organization's staff and after a while this information changes into the working methods and skills and new working and skill fronts are created.

\subsection{Institutionalization of Change and Innovation}

One of the hallmarks of human development is that they constantly produce and apply new thoughts and in other words they are creative and innovative. Sufficient information is the context and axis of creativity in order to combine information and make new collections which have new characteristics and applications transfer (Fasanghari, Roudsari, \& Chaharsooghi, 2008). Institutionalization of change and innovation is dependent on how 
human deal with the produced information. In an interactive process, IT and human affect each other and if it is acted properly, change and innovation are institutionalized (Giviyan, 2001). When the IT penetration and acceptance by humans is low, this situation will not change and all the effort and energy is spent on maintaining the status quo. When IT penetration is high but is not accepting, there are no customers for information and no results are achieved. And when penetration of information is low and its acceptance is high, creativity is achieved in the atmosphere of information thirst and it is desirable that technology penetration is high and its acceptance is also high which results in the combination of creativity and change.

\subsection{Strengthening Cognitive Skills}

Having cognitive skills is one of the signs of a developed human; Cognitive skills are the ability to understand that various functions of an organization are linked together and changes in any of the sectors do not necessarily affect the other parts. Cognitive skills is not something that can be created with a theoretical training course

but staff's thinking must change and cognitive ideas change into cognitive action (Soltani, 1999). systems thinking is the underlying of cognitive skills and cognitive skills can be created and developed through IT, this is because IT is a system that teaches systematic and cognitive skills of thinking and acting to people. IT system in practice causes people to put Beginning, process and system performance in a collection and understand it and they are equipped with cognitive skills and abilities which results in the connection of beginning of the process and its results (Nejdairani, Rasouli, \& Behravesh, 2011).

\subsection{Strengthening Decision-Making Skills}

Decision-making is a process in which information plays a major role, First, the required information must be provided to combine the information and make a decision. Information technology makes the employees choose process and use the information related to the required decision from among the produced information. In the decision-making process, employees learn how to use the information. We are accustomed to decide with any information that we receive which is not professional. Relying on the opinions of laymen and non-experts mislead people, consulting with non-professionals causes people to make mistakes in decision making (Fadavi, 1986). One of the indices of a developed human is that he replaces unauthentic sources with reliable sources of information which requires the existence of information structure. It means a time when information technology exists and is available. People have to make decisions based on accurate information and in fact, management information systems such as Management Support Systems and Decision Support Systems can offer updated, quick and proper information in order to make decisions with the minimum mistakes. Accordingly, people benefit from scientific decision-making skills, and it leads to decision-making skills in practice (Soltani, 1999).

\section{Conclusion}

Information technology as a set of ideas generated by hardware mechanisms is available for individuals and organizations and plays a major role in the development of human resources, it is one of the key elements in gaining competitive advantage for enterprises in the information age (Ghorbani \& Sangani, 2011). Today, having knowledge and changing and 
directing it in human resources through information technology is easily done and develops employees of an organization or community in various aspects. Information technology has an effective role in the development of professional skills, contributing to the institutionalization of change and innovation, strengthening cognitive skills, strengthening decision-making skills, creating research spirit among employees and contributing to the formation of the standard thinking and it can lead to balanced and multi-faceted human development. In the information age the only organizations will be able to survive that:

Firstly, it has empowered and knowledgeable employees that will enable the organization to compete with other competitors in the market and business environment and secondly it can maintain and improve these appropriate personnel by paying attention to them and updating their knowledge and skills. In this regard, the most important factor that should be considered by organizations is the topic of ICT. What organizations in this field should always consider is to ensure that the use of these technologies in long-term will bring high competitive advantages, they should not pay attention to the short-term outcomes. Many companies have significant experience in this area. In many cases, they have claimed that in today's dynamic business environment. The most important factor to maintain and improve their position is nothing but ICT and linking it with human resources development and involvement of employees and managers in this area.

\section{References}

Ahmadi, A. (2011). The Role of Information Technology in Planning the Organization Resources E-Journal of Elites, Elite National Foundation of Azerbaijan-e-Sharghi, p.15.

Abile, K., \& Movafaghi, H. (2003). Modern management concepts. Publication Shiveh, Tehran, Iran.

Baldwin, T., \& Ford, J. K. (1988). A review a direction for future research. Personnel Psychology, 41, 63-105. http://dx.doi.org/10.1111/j.1744-6570.1988.tb00632.x

Benavente, J. M., \& Lauterbach, R. (2008). Technological innovation and employment: complements or substitutes? The European Journal of Development Research, 20(2), 318-329. http://dx.doi.org/10.1080/09578810802060744

Davoudi, A. (1999). Development of human resources and administration. Tadbir Journal Tehran, 41.

Drucker, P. F. (1993). The Future of Contingent Work. Oxford, UK,

Fadavi, A. (1986). Director and standardization, Diversification and minimalism. Tadbir Journal, 65, 29.

Fasanghari, M., Roudsari, H. F., \& Chaharsooghi, K. (2008). Assessing the Impact of Information Technology on Supply Chain Management. World Applied Sciences Journal, 4(1), 87-93. http://dx.doi.org/10.1109/isecs.2008.208

Gabcanova, I. (2013). The role of Information technology in Human Resources management. Strategic Human Resource Management at Tertiary Level, 65. 


\section{Macrothink}

Journal of Social Science Studies

ISSN 2329-9150

2016, Vol. 3, No. 2

Giviyan, H. (2001). The impact of the limitations of new information systems in the organization. Tadbir Journal, 114, 43.

Ghorbani, M., \& Sangani, S. J. (2011). Role of Information Technology on the Organizational Effectiveness in Mashhad City Hall. World Applied Sciences Journal, 13(9), 2095-2107.

Hajizade Moghadam, A., \& Vajdi Dastgerdi, S. S. (2010). Information Technology Project-based Organizations and Employee Satisfaction: A Case Study of Iran. World Applied Sciences Journal, 10(10), 1176-1184.

Kolinsky, R. (1998). The new competition and human resources: how disadvantaged are low income LDCs? Paper prepared for a conference on Globalization and Learning, September, Oxford, 1998.

Koellinger, P., \& Minniti, M. (2006). Not for lack of trying: American entrepreneurship in black and white. Small Business Economics, 27(1), 59-79. http://dx.doi.org/10.1007/s11187-006-0019-6

Mahmodi, M. (1993). Impact of information technology on human resource management. Tadbir Journal, 172.

Mir Fakhraee, S. H. (2001). Characteristics of virtual organizations. Tadbir Journal Tehran, $117,51$.

Mohammadnezhad, F. (2015). Re-engineering information technology and human resource management. Tadbir Journal, 94, 41.

Nejdairani, F., Rasouli, R., \& Behravesh, M. (2011). The Effect of Applying Information Technology on Efficiency of Parks and Green Space Organizations: A case Study. Middle-East Journal of Scientific Research, 10(2), 224-232.

Roshan, M. (2003). Human Resource Development, Institute for Studies in Industrial Development and Renovation Organization of Iran. Tehran.

Soltani, I. (1999). The role of TPM in the human resources development. Modiriyat Journal, 40,58 .

Walwyn, D. (2003). Biotechnologists, in: Human Sciences Research Council, Human Resources development review 2003: Education, employment and skills in South Africa (Cape Town, HSRC and East Lansing, Michigan State University Press),

Wars, S. H. (1998). The advent of information technology. Tadbir Journal, 87, 54.

\section{Copyright Disclaimer}

Copyright for this article is retained by the author(s), with first publication rights granted to the journal.

This is an open-access article distributed under the terms and conditions of the Creative Commons Attribution license (http://creativecommons.org/licenses/by/3.0/). 